\title{
Psychophysiological readiness of students to work in the field of clinical speech therapy
}

\author{
Marina Skuratovskaya ${ }^{1 *}$, Tatyana Klimova $^{2}$, Natalya Fedko $^{3}$ and Natalya Mayatskaya ${ }^{3}$ \\ ${ }^{1}$ Don State Technical University, Department of Psychology, Pedagogy and Defectology, \\ 348000 Rostov-on-Don, Russia \\ ${ }^{2}$ South Federal University, Academy of Psychology and Pedagogy, 1164065 Rostov-on- \\ Don, Russia \\ ${ }^{3}$ Stavropol State Medical University, Faculty of Humanities and Biomedical Education, \\ 355017 Stavropol, Russia
}

\begin{abstract}
The professional training of a clinical speech therapist traditionally focuses on the formation of professional competencies, motivation, and the ability to develop professionally, while the problems of coping with chronic emotional stress are common causes of professional deformations in them. It has been suggested that a high level of speech therapist's readiness for professional activities, along with the individual typological characteristics of the personality described in the professiogram, is positively associated with a number of psychophysiological characteristics. An empirical study of personality traits, psychoemotional state, psychophysiological reactions, the adaptability of speech therapists $(\mathrm{N}=56)$ was carried out using the psychophysiological testing device "UPFT-1/30 Psychophysiologist" ("Medicom MTD"). For the survey of teachers of three Russian state universities $(\mathrm{N}=37)$, providing education clinical speech and language therapists were used the methods of analytical professiogramme E. M. Ivanova.
\end{abstract}

\section{Introduction}

In accordance with the Federal educational standard of higher education in direction 44.04.03 "Special (defectological) education", professional training of clinical speech therapists is carried out on the basis of a competency-based approach. In a few sources analyzing the professional activity of a speech therapist, the main attention was paid to particular issues of the content of professional competencies (communicative, adaptive, reflective, etc.), their content, issues of professional training, etc. [1, 2, 3, 4].

The studies presented in the specialized literature on the development of a speech pathologist professionogram include the following components:

\footnotetext{
*Corresponding author: marinasku@yandex.ru
} 
- analysis of the labour activity of a speech therapist that reveals the subject and result of labor, the main activities, the necessary knowledge, skills and professional competencies;

- a psychogram that describes the qualities that ensure success in the profession in accordance with its goals and objectives, professional abilities and psychological contraindications;

- a sociogram reflecting the socially significant personality traits of a speech therapist.

Nevertheless, studies that would consider not only psychological characteristics, but the psychophysiological aspect of professional readiness for speech therapist activity are not presented in the literature $[5,6,7,8]$.

The professional activity of a speech therapist involves a combination of a creative approach in applying existing knowledge and the ability to think adequately, the ability to cope with stressful situations, perseverance and attention to detail, stability and control of the psychological state. Developed facial expressions, coordination and accuracy of motor functions, possession of extralinguistic means of expressiveness (pitch, tempo, intonation, pausing, etc.) and, of course, developed speech and communication skills are required [9, $10,11,12,13,14,15,16]$. The described indicators are, in our opinion, important for determining professionally significant characteristics of a speech therapist and determines the importance of data on the psychophysiological readiness of students to work in the field of clinical speech therapy. Therefore, the search for ways to obtain objective, reliable data on the psychophysiological characteristics of respondents in a short time with an automated form of organizing research and the ability to systematize the information received can be used to solve the problems of career guidance and individualization of the educational process [17].

Since 2014, the internetworking program for the training of masters "Clinical Speech Therapy" in the direction 44.04.03 "Special (defectological) education" has been implemented at Southern Federal University, Stavropol State Medical University, and later at Don State Technical University. Our experience with students studying under this program shows that the analysis and consideration of the psychophysiological characteristics of students studying speech therapy, the psychophysiological aspect of preparing a clinical speech therapist, should be important components of individualization of professional training of future specialists. In this regard, we conducted a study of individual typological and psychophysiological personality traits that are significant for the professional work of a clinical speech therapist, individually-typological and psychophysiological properties of personality.

\section{Methods}

We suggested that in addition to the components considered in the literature, certain psychophysiological characteristics are also important indicators for assessing the readiness for professional activity in the field of clinical speech therapy.

The study included an expert survey of teachers implementing the master's program "Clinical speech therapy" at the southern Federal University, Stavropol state medical University, don state technical University, with experience of 7-12 years $(\mathrm{N}=37, \mathrm{M}=$ 42.34, $\mathrm{SD}=12.93$ ). Also in the empirical study involved students 2 master's courses enrolled in the program "Clinical speech therapy" $(\mathrm{N}=56, \mathrm{M}=25.34, \mathrm{SD}=2.95)$.

The research procedure included the following steps. To determine the professionally important individual-typological characteristics of the specialist speech therapist using the method of focus groups on a sample of teachers of the three state universities conducted a content analysis of the results of analytical professiogramme E. M. Ivanova and free Association. At the next stage, using the method of "expert assessment", the masters of 2 
courses of the direction "Clinical speech therapy" were divided into 2 groups: the main one with a high level of preparedness (group A) and the control one with a low level (group B). The data obtained were refined during observation and conversations with teachers.

The following main parameters of readiness were investigated: 1) ability to act in nonstandard situations, to critically analyze and evaluate own activity; 2) communication in oral and written forms to solve the problems of professional activity; 3 ) the implementation of educational and corrective work using innovative psychological and pedagogical technologies; 4) ensuring the interaction of workers in the fields of education, healthcare and social protection when solving urgent correctional and pedagogical problems; 5) diagnostic and advisory activities. Indicators of the level of readiness were the sum of points received by the respondents as a result of summing up all the expert assessments for each parameter, as well as the coefficient of agreement of the experts.

In conclusion, a comparative psychophysiological study of students was conducted to identify the psychophysiological and individual typological properties of respondents with different levels of readiness for professional activity. The study was conducted using a psychophysiological testing device UPFT 1/30 "Psychophysiologist." The duration of the procedure averaged 120 minutes. Based on the obtained data, when assessing the psychophysiological components of suitability for professional activity of a clinical speech therapist, the following methods were used: a complex visual-motor reaction (SZMR-3), a questionnaire "Well-being, activity, mood" (V. A. Doskin, N. A. Lavrentieva and etc.), a multi-level personality questionnaire (MLO) "Adaptability" (A.G. Maklakov, S.V. Chermyanin). The evaluation parameters were: stability and switching attention, the current psycho-emotional state of the individual, his emotional stability; mobility, speed, rate of flow of functions, well-being, manifestations of fatigue; characteristic features and communicative abilities of respondents.

The diagnostic procedure was carried out once, individually, was uniform, the time for completing tasks was not limited. Processing of the obtained data was performed using the SPSS.21 program (Kendall concordance coefficient (tay-b), Mann-Whitney U-test).

\section{Results}

The analysis of the results of the survey of 37 teachers of the universities of SFU,SSMU, DSTU showed that the work of a speech therapist includes strategic planning for the diagnosis and correction of speech defects, the willingness to quickly select the necessary tools for solving professional problems, understanding the causes and mechanism of the existing violations, empathy and attention to the patient (the coefficient of consistency of experts tay- $b \leq 65.5-82.7)$.

Among the professionally significant qualities of a speech therapist identified by experts, the following prevailed: emotional involvement $(85 \%)$; stable positively colored emotional background (57\%); emotional self-regulation (57\%); control of speech activity $(29 \%)$; flexibility of thinking, ability to work in non-standard situations $(42 \%)$; tolerance $(85 \%)$; reflexivity $(71 \%)$; communication skills $(71 \%)$; voice proficiency $(57 \%)$, etc. The results of the assessment by the experts-teachers of students allowed to identify two groups of students who significantly differ in levels of readiness for speech therapy. Let us dwell on the description of psychophysiological features of the sample of group A, with a high level of readiness for professional activity.

The results of the study showed that in a sample of students with a high level of psychophysiological readiness for speech therapy (group A) significantly more common are psychophysiological indicators of visual-motor reactions, which indicate an average level of CNS activation $(U=, 030$, at $\mathrm{p} \geq 0.5$ ). At an average rate of operation, stability of reactions and stability of regulatory mechanisms $(U=, 065$, at $p \geq 0.5)$ are observed. As the pace of 
work increases, the quality of tasks is slightly reduced $(U=, 040$, at $\mathrm{p} \geq 0.5$ ). For students from group A is characterized by an optimal combination of speed and error-free action. The force of the excitation and inhibition processes is at a high level with the predominance of the first ( $U=, 001$, at $p \geq 0.5$ ), the mobility (switching) of the excitation and inhibition processes at the average level.

Assessment of current psychoemotional state shows average values on scales assessing "well-being" ( $\mu=4.8)$, "activity" $(\mu=4.5)$ and expressed above average performance on a scale of "mood $(\mu=5,5)(U=, 035$, at $p \geq 0,5)$. Such a ratio of scales is observed at a sufficiently high efficiency against the background of interest in the activities performed.

Multilevel personal questionnaire showed the average level on a scale of "situational anxiety" $(\mu=5,6)$, the lack of marked symptoms on the scale of "mental stress" $(\mu=4,06)$ and "maladjustment" $(\mu=5,0)$. For students from group A was characterized by an average level on the scales of "neuropsychological stability" and "behavioral regulation" $(\square=4,1)$, developed communication skills $(\mu=4,5)$ and normative behavior $(\mu=5,8)$. The adaptive potential was within the norm $(\mu=2,8)$. Students with a high level of psychophysiological readiness for speech therapy (group A) are significantly distinguished by social activity, adaptability to changing conditions $(\mathrm{Hs}=4,6 ; \mathrm{U}=, 020$, at $\mathrm{p} \geq 0,5)$, the ability to feel the nuances of interpersonal relationships, humanistic orientation of interests ( $\mathrm{Mf}=5,3$; $\mathrm{U}=, 001$, at $\mathrm{p} \geq 0,5)$, openness to social contacts $(\mathrm{Si}=5,6 ; \mathrm{U}=, 030$, at $\mathrm{p} \geq 0,5)$.

\section{Conclusion}

The study revealed the relationship between the level of formation of psychophysiological readiness of students to work in the field of clinical speech therapy and the mobility of the nervous system, the ratio of excitation and inhibition, the level of formation of sensorimotor acts, levels of activation and functionality of the Central nervous system. The study made it possible to determine the individual-typological prerequisites of readiness for speech therapy work, as well as to test the program of diagnosis of psychophysiological readiness for speech therapy using biofeedback technology. The obtained data formed the basis of training on training of undergraduates in skills of self-regulation of psychophysiological state taking into account the individual psychophysiological status for the successful solution of problems of professional activity in the field of clinical speech therapy.

\section{References}

1. E.E.Artemova, L.A. Tishina, O.S. Glukhoedova, M.A. Adilzhanova Bulletin MSUH. Ped. and Psy. 3, 9 (2013)

2. A.V. Nikiforova, TSPU Bulletin 9 (137), 44 (2013)

3. E.V. Koltakova, Professionogram of a speech therapist teacher: designing the content of vocational training and advanced training (Sputnik, 2011)

4. L.D. Tsaturian, V.S. Nikolsky, V.D. Perkhurova, D.A. Androsova, R.Kh. Kuvandukova, E.O. Melikbekyan, A.A. Shevyakova, Med. N. North Caus. 9, 92 (2014)

5. D.Georgieva Folia Phoniatrica et Logopaedica, 62 (5), 217 (2010)

6. D. Georgieva, T.Woźniak, S.Topbaş, N.Zemva, M. Duranovic Folia Phoniatrica et Logopaedica 66, 183 (2014)

7. M.S. Overby International Journal of Language and Communication Disorders 53(1), 101 (2018)

8. W. Paans, I. Wijkamp, E. Wiltens, M.V. Wolfensberger Journal of Multidisciplinary Healthcare 6, 347 (2013)

9. T.V. Klimova, M.L. Skuratovskaya, MEJSR 16 (10), 1441 (2013) 
10. Pascoe, L.J. Breen, N.Cocks, International Journal of Language and Communication Disorders 53(3), 542 (2018)

11. J.K. Sekhon, J.Oates, I. Kneebone, M. Rose International Journal of Language and Communication Disorders, 54(3), 321 (2019)

12. E.Söderpalm Folia Phoniatrica et Logopaedica 58 (1), 59 (2005)

13. K.Vitásková ICERI2013 Proc, pp. 4285 (2013)

14. N.I. Boltakova Vest.TGGPU, 26, 307 (2011)

15. L.A. Borovtsova, N.N. Ivanova Tomsk State University Journal, 11 (115), 136 (2012)

16. A.A. Dmitriev Siberian Pedagogical Journal 3, 98 (2013)

17. N.E. Vodopyanova, Burnout Syndrome: Diagnosis and Prevention (SPb .: Peter, 2009) 